\title{
Chapter 12 \\ Employee Representatives and Participation in the United Kingdom
}

\author{
Miguel Martínez-Lucio and Arjan B. Keizer
}

\subsection{Introduction}

This report draws on semi-structured interviews with leading Human Resources (HR) managers in ten organizations. They were approached through a range of contacts and prior research links, and can be considered representative of medium to large organizations in various sectors of the British economy. They are unlikely to be fully representative of the overall United Kingdom (UK) attitude towards ERs and social dialogue as they are mostly firms with embedded participation traditions of one form or another. Nevertheless, they appear to present us with an opportunity to discuss various aspects of the British labor and employment relations system.

The research examined two multinational petrochemical firms (in one case two interviews were conducted with a national and international manager in employment relations), a European investment bank, a leading national supermarket, a large city council, a central government organization related to employment relations activity, a traditional large research-led British university, a charity, a health service trust (part of the National Health Service), and a local housing organization that also runs several academy schools. In the case of the multinational organizations, the focus was solely on UK operations.

In addition, the report draws upon the findings of an accompanying survey. However, as explained in greater detail later in the report, there was a low response rate and the findings can be used tentatively at best.

M. Martínez-Lucio $(\bowtie) \cdot$ A. B. Keizer

Manchester Business School, The University of Manchester, Manchester, UK

e-mail: miguel.martinezlucio@mbs.ac.uk
A. B. Keizer
e-mail: arjan.keizer@mbs.ac.uk
(C) The Author(s) 2015

M. Euwema et al. (eds.), Promoting Social Dialogue in European Organizations,

Industrial Relations \& Conflict Management 1, DOI 10.1007/978-3-319-08605-7_12 


\subsection{The Historical Context and Developments in Employee Representation}

The UK has been classified as a liberal market economy (Hall and Soskice 2001) with a market-based employment regime (Gallie 2007) and an industrial relations regime described as (liberal) pluralism (Crouch 1993; Visser 1996). The state is relatively powerful but has generally acted in a less interventionist manner compared to northern European nations. In accordance with the 'voluntarist' tradition of industrial relations, TUs are predominantly 'competitive' in style (Meardi 2004). Hyman (2001) locates UK trade unionism between the competing interests of a class and market identity, due to its militant defense of the economic interests of union members and its suspicion of societal instruments of reform in favor of free collective bargaining, although this has been changing. There are few positive legal rights to collective representation per se. Collective representation is through recognition agreements that have been reached between employers and their workforce or following a ballot in favor of recognition. Holding such a ballot is not straightforward due to the need to have a certain level of TU membership prior to the vote (Perrett 2007). There are no works council elections as exist in a large part of the European Union (EU). The forms of representation that exist tend, in general terms although there are other forms, to be as follows:

1. Recognized unions who bargain with management and are consulted by them;

2. Consultative and information-based committees that involve elected ERs and/or TUs; and

3. Information and consultation committees that are based on (non-union) employee representatives selected by management.

Much of this diversity is due to the way in which industrial relations in the UK were regulated 'from below' and without direct state intervention for large parts of the early to mid-twentieth century. It is further linked to the political questioning of collective representation throughout the late twentieth century and early twentyfirst century. Consultative mechanisms have been to a great extent disconnected from strong and formal legal pre-requisites, although in the public sector there has been a more extensive tradition of consultation dating back to the 1920 s and 1930 s (Sheldrake 1988). As a consequence, the structure of employee representation in the UK is distinct from the main European approach. Formal employee representation at organizational level is lower than in other European countries. This includes southern European countries that may not be characterized by corporatism and social partnership but nevertheless have a strong institutionalization of employee representation (European Commission 2009).

Increasingly, since the 1980 s, there has been a shift from the former dominance of a trade union-style approach towards alternative types of 'management-led' employee representation. It can be argued that the UK is now a dual system of representation in two senses. 
Firstly, union and non-union forms of collective representation sometimes coexist in the same organization, although often within different divisions. However, as the findings of the study illustrate, most forms of participation within organizations have either a (strong) union role or rely on an alternative form and this appears to be different from the situation in many European countries. In the public sector, there are still strong collective systems based on trade unionism while in the private cases there tends to be a much greater role for alternative arrangements. Here worker representation is often developed by non-union elected employee representatives, also because union members - to the extent present - normally stand as individuals and not as representatives of TU in elections to consultative forums or councils. In all cases studied, the members on the forum were 'appointed' through elections, although these were sometimes fairly informal. Alonso (2001) views such developments in general as representing a new micro form of corporatism where business interests and objectives take precedence over social ones.

Secondly, the increase in more direct forms of representation and consultation is leading to the fragmentation of labor relations and has contributed to another dualism between more collective and more individual forms (Marchington and Wilkinson 2005). Instruments such as workforce surveys, quality circles and team briefings are becoming an important feature of many firms and workplaces, although this research has not focused on this dimension.

The findings show the UK case as a heterogeneous form of representation which has evolved over time, although the extent of independence among employee representatives and the autonomy of the representative processes are to be questioned at times. There is a wide diversity in structures, possibly much more so than on the continent, with a clear distinction between more established union structures and more recent participation initiatives. Within this diversity, there are further 'groupings' which show (strong) similarities: the public organizations, the large multinational companies (MNCs) with both UK and European participation structures, and the (smaller) domestic organizations where the informal aspects of relationships are paramount. In this respect, there is more to participation than is suggested by the aforementioned qualifications of the UK as a 'liberal market economy' with a voluntarist and liberal tradition in industrial relations. In many ways what we found was a variety of systems of participation and complex narratives sustaining and legitimating processes of representation. The latter illustrates an important degree of 'negotiation' over participation in relation to its legitimacy and effectiveness. Even when initiatives are management led, and even when the initiatives appeared mostly symbolic, the need to try and construct a framework of legitimacy was evident, even though the motives were normally concerned with controlling the remit of participation.

The relationship between union and non-union forms of participation proved particularly interesting. As mentioned, there were few organizations where both workers' forums and unions played an active role. Some interviewees suggested that the forums or councils were there to counter potential union development. If there was both a forum and a union, this often concerned different parts of the organization such that the two would remain separate. For example, in the housing trust 
the main part of the organization had an employee forum while the schools were unionized. At the petrochemical MNCs, there were small unionized areas, with the majority of employees represented only through the employee forum. There are also cases where HR managers said that there was no call for unions, partly because of the perceived success of the forum. So we saw complex labyrinths of representation and participation, which doubtlessly present opportunities to management but also present challenges to workers and even the organization as a whole.

The structures of participation were sometimes highly layered and complex as in the large national supermarket and the large city council which were both unionized. This raises specific questions about the capabilities of representatives (particularly further down these layers) and the location of the appropriate level or channels to discuss strategic matters. There were also special 'joint' management and worker representative working groups in some instances, related to the development of specific operational matters such as grievance and discipline which tended to contribute to the complexity. The time and resources provided to prepare for such work were more regulated where there was a stronger tradition of union representation. In the case of employee forums, the allocation of time was often limited to the meetings and was often at the discretion of and the responsibility of individual managers. We therefore need to be careful when discussing these forms of representation. Their constitution and structure are complex and not subject to clear regulatory guidelines, making them increasingly management-determined. As we will discuss later, this places management in a curious position of responsibility.

\subsection{Current Situation of Employment Relations According to HR Managers}

This section considers various dimensions in the relationship between HR managers and the systems of participation by focusing on the trust within these relationships, the attitudes and competence of ERs, the management of conflict, and the influence of the EU.

There did not appear to be any major issues relating to trust, according to the HR managers, even in the more trade union-oriented systems. In the case of the public sector (health service, civil service organization and the local authority), the experience and stability of worker representation meant that there was a long history of dialogue and ongoing reciprocity in the relationship between management and unions. While some managers spoke of the continuing influence of 'traditional' ways of thinking these were often commented on while referring to the overall flexibility and engagement of trade union representatives. In the private sector, the predominantly non-union ERs are less independent and are not backed up by a separate organizational structure as provided by a TU. With the remit of forums more limited and a challenge to management's decision-making role unlikely, issues of trust appear to be less critical. One therefore needs to be cautious of what is meant by trust. There was concern from HR managers that employee representatives did 
not always have the experience or continuity required to be fully engaged with many matters. In these cases it was felt that there was no support for the individual, or that they lacked the required background and knowledge of the organization's history to allow them to contextualize and develop more proactive decision making. However, 'trust relations' - in general - do exist according to the HR interviewees, and confidentiality clauses or expectations on key issues were common and mutually respected. It was rare to see cases or instances where such confidentiality clauses - which are important for many partnership arrangements (Martinez-Lucio and Stuart 2005) — had been undermined. Overall, the evaluation of these roles and structures was positive, even in the more organized and traditional public sector organizations where the project identified a broad set of dialogues on organizational change and the response to welfare and state reforms. In fact, the dialogue appeared to be stronger here.

In many respects - as also outlined by Oxenbridge and Brown (2002) — the stronger cases of dialogue and participation showed extensive informal relationships and discussion between management and worker representatives. The findings illustrated how the relatively positive perceptions of trust emerged from informal and stable relationships. According to various HR managers the ability to understand and create a dialogue requires investment and a learning frame which sees individuals jointly work through critical incidents. In some cases (e.g. the charity), it was explicitly acknowledged that the development of a trust-based relationship requires long-term investment and engagement and cannot be taken for granted. In the case of the investment bank it was argued that it cannot be taken for granted that people will just involve themselves. In this respect, there was awareness in those cases with a less than collective approach that there was a risk and a challenge in not having 'ready-made' representatives or sources of participation as in trade unions. In many cases where there was no direct union presence, or where the form of representation ran parallel to and was not linked with the union structures of bargaining, the participatory structures of the forums or councils were more ad hoc and varied in their approach. This indicates that the burden of representation falls on organizations to administer. The fact that this form of representation can be open to abuse without a generalized process of representation and independent participation adds to the challenges involved.

In terms of attitudes and competence, there were mainly positive responses although HR managers generally felt that at lower levels of representation and participation there was some lack of understanding about how to form agendas for discussions and a lack of communication skills. Time management, agenda setting and preparation for meetings were some of the other issues raised by management although these were not seen as major problems in most cases (in the private sector cases these did appear to be more of an issue). In one case, there was reference to a 'verbose' yet effective representative in an employee forum. This was explained in terms of the individual having once been a trade unionist. The level of experience and ability was much stronger in more unionized organizations and in the public sector. Here the union provided support to the representatives and the dialogue was 
much more continuous and grounded, although political differences between some unions in the case of the health and local government organizations were noticeable. Several interviewees (e.g. at the university, the housing trust and the city council) expressed concerns about the competence of some union representatives engaged at departmental level. The supermarket representative also expressed concern about the ability of representatives and the difficulty of recruiting them to the role lower down the chain of participation, at the level of the individual stores.

There were wider concerns about the availability of ERs. The more trade unionorganized cases seemed to be able to generate representatives and resources for representation, although this was not the case in (private) organizations with few union members. In some cases, there were comments regarding the lack of representatives in the worker forums and lack of enthusiasm with regard to becoming a representative. This was the case, for example, at individual store level in the supermarket chain and in the non-unionized bank. One explanation could be the lack of understanding about such roles within an environment where participation is very much managed from above and not organically and independently developed within the workforce. There is also the possibility that such representative roles are highly complex and require extensive individual commitment (see Munduate et al. 2012). But the lack of interest or engagement could also be due to the limited remit of councils or local forms of participation (or at least the perception that this is the case). In some cases, interviewees emphasized the importance of 'role models' (e.g. the charity) or the importance of leadership among worker representatives (e.g. the housing trust). In others, there was some modest 'targeting' of 'promising' candidates due to limited interest among workers, or management not being satisfied with the incumbent member. There appeared to be general concern about the recruitment and renewal of employee representatives in those organizations without TUs.

The issues of trust, attitude and competence are in many cases linked to the importance of training. The research identified an interest in training representatives in more individualized non-TU cases. Training provision was sought from various bodies including the private Involvement and Participation Association (IPA) and the public Advisory, Conciliation and Arbitration Service (ACAS) to try and create frameworks for a more meaningful dialogue and to put in place more sustainable forms of representation. In most cases there were "away days" and attempts to sustain dialogue through social events and the use of pre-meetings and informal dialogue held away from the forums. Several organizations (including the petrochemical companies, the housing trust, the investment bank and the charity) engaged with such forms of training as a vehicle to support and mentor individuals into these new roles. In effect, training allows for the remaking or making of a history of participation which has been absent from such a context or which has been subject to extensive change. Managers also reported examples of different groups coming together in the forums which then 'shaped themselves' and self-regulated each other. This was the case in, for example, one of the petroleum MNCs that had emerged from a previously public sector context with a more regulated background. In this respect, the space of representation is itself a learning space and can contribute to an ongo- 
ing dialogue if the support is there. This was apparent in those cases where there was limited or no union presence. In effect, not having anyone to delegate to, or rely on, for generating representation meant that the firm had to step in and generate it themselves, with all the operational and ethical issues this can give rise to.

We have to be mindful of the fact that not interviewing ERs meant that we were constrained in terms of understanding the real panorama of conflict and difference. While the HR managers involved were generally open and appeared to be sincere in outlining problems; it is not possible to fully verify the findings as industrial conflict is sometimes seen as a sign of weakness or failure in HR administration. In the public sector, interviews referenced strikes, but these were national 'days of action' related to the political context and government-led austerity programs. They illustrated the important impact of national outcomes on local industrial relations for many public organizations (for example the health service trust, central government organization, universities and local authorities). TUs were engaging heavily in minimizing, where possible, the effects of the neo-liberal and austerity policies of the 2010-elected Coalition government. There was a background of political unease due to the restructuring of the state and politicized responses by unions engaged in opposing the social impact of the public spending cuts. However, these issues were deemed (curiously) to be external to the national and local forums and in partand ironically_ did not systematically disrupt local discussions. Relations between management and unions were therefore in broad terms still intact. The 'external' and political nature and origins of the conflict - and the decisions leading to it - allowed management to dissociate itself from the reasons and drivers for austerity measures. It enabled a curious organizational 'solidarity' or 'understanding' with TUs in their forums to ensure that the reductions in jobs and state resources were evenly and 'fairly' distributed (although this remains a matter of interpretation). This was a robust test of the systems of representation within the public sector and their ability to absorb pressure and to create - to an extent - a basis for a longerterm strategic dialogue. It very much undermined the image of the public sector and trade union representatives as being antiquated as in fact they are heavily engaged in a range of discussions and difficult decisions. However, in some instances it was felt that over time and with further cuts to public services this dialogue would possibly deteriorate, and mutual gains for both sides would be hard to find.

In the private sector, conflict was less common. There were differences of opinion on various aspects but the absence — or virtual absence — of conflict meant that employee representation and relations were not seriously tested. The absence of key conflicts was in part due to the absence of unions, the weakness of unions or the presence of unions with a more business or market-facing identity as in the case of the supermarket. Moreover, the forums in such contexts would not necessarily oversee or deal with conflict in general. There was a tendency to engage with sensitive issues of change in some organizations but always according to parameters set by management. Interestingly some organizations, with the housing trust as the most striking example, stressed how they wanted the forum to consider more strategic rather than day-to-day operational issues. This relates back to how agendas are set and how such forums are seen as part of a longer-term dialogue. It does not always 
have a decisive effect on difficult topics but such topics were brought into some of the forums and in those cases, where there was a more systematic and strategic approach to restructuring, it became a testing ground for future proposals. These tended to be organizations with a history of regulation and representation such as the petrochemical companies that had emerged from the public sector. Once more, organizational memory was a curious additive in influencing the nature of representation (Martinez-Lucio and Stuart 2007).

Finally, awareness of EU-level social dialogue initiatives was low in most-although not all - cases. Firstly, in the public sector the systems of representation were highly advanced and similar to some extent to the Works Council models of many European countries in terms of social dialogue and relations. Second, in the companies with a weaker union presence, where they had been using information and consultation forums for some time, these were fine-tuned and developed only partially in the light of the EU information and consultation of employees (ICE) initiatives. In the UK, these initiatives have therefore tended to be linked into existing union and non-union models. There may have been some input in terms of the early initiatives but the EU dimension is not integral in any explicit manner nor very visible. The research confirmed that the processes of dialogue have been adjusted nationally and locally to fit the organizations in various ways. At national level there has been no major development in the process of dialogue except that national structures of representation and discussion among public sector employers and unions took some pressure off the local level in terms of dealing with the implementation of decisions.

It is clear that the European Works Council (EWC) Directive has been adhered to in the main by the UK. The MNCs in our research had a EWC. Yet there appears to be a clear divide - or gap — between national and European level arrangements in such firms. It appears that there is little influence in the sense that those UK representatives on the EWC tend not to introduce EWC practices or routines within UK forums or councils. In some cases there is some spill-over effect and an interesting aspect was put forward by the two interviewees at one of the petrochemical MNCs. They both discussed how participation in the EWC shapes the attitudes of UK forum representatives as they see much more consultation in Europe. However, opinions differed on the impact. One interviewee stressed a positive influence while the other pointed out how a cultural clash in approaches to the EWC meetings illustrates and even leads to a strengthening of a different attitude in the UK. The national representatives who were also on the EWC experienced more 'aggressive' behavior from representatives from countries like Germany and France and tended to disengage from it. Something similar was noticeable in the investment bank where the interviewee also stressed this different attitude between British and some other European worker representatives. So there was a realization that the forums in the UK werewhen linked less to a union approach and system of representation-different in nature to the perception of a European approach. Yet such a 'more assertive' approach would tally with the public sector. In effect, the distance from the EU is apparent in the newly-emerging management or company-driven systems of representation and 
participation that are more business orientated, and where independent representation is not clearly developed.

\subsection{The Survey}

As already mentioned, response to the accompanying UK survey was very low and for this reason we consider the findings highly tentative. The survey was not based on systematic sampling but distributed through "snowballing" after the link to the interview was initially sent to the range of identified HR managers approached for the interviews. They were subsequently asked to send the survey link to other HR managers in a range of organizations that they might be familiar with. The UK team also sent out an email on two occasions to a database of over 100 UK-based HR managers who formed part of the Manchester Business School alumni body. This was followed up with individual emails to over 1100 UK-based HR managers included in a database acquired by the University of Manchester from a specialist research company. A fourth initiative came from a former student of the Manchester Business School who used the social media organization LinkedIn to send out the request to participate in the survey to a group of 1200 employment relations specialists. In spite of the large set of individuals contacted, the number of responses remained low, possibly suggesting a problem with the sensitivity of the topic in the UK. The UK case study authors believe that the low response is due to questions in the survey which asked the manager to assess the abilities of representatives with whom they could have a personal link or working relationship. The nature of the participation system in the UK is also, to a large extent, more complex and with a lower level of representation and participation compared to most other EU countries. There is also less collective representation, with more firms without ERs compared to the situation in other parts of Europe. The absence of clearly established institutional structures for social dialogue may have an important impact on the visibility and awareness of issue of representation. We felt that the low response may reflect the fact that such practices are less ingrained within the UK system and characterized by lower levels of engagement with representatives. Our cases were distinct as we selected them because of the presence of some type of participation forum within their organizational context. This may explain why the qualitative data is at odds with the survey findings (Fig. 12.1).

When it comes to the survey outcomes, there are some findings in comparison to the European average albeit that their interpretation seems to require some conjecture. The figure-with significant differences circled-shows how trust in industrial relations is higher in the UK than in Europe $(\mathrm{M}=3.62$ vs. $\mathrm{M}=3.31)$. The relatively high level of trust appears to fit the interview findings although its interpretation is not straightforward as it appears counter-intuitive and there may be no single explanation across all cases. In unionized organizations, it may relate to the established character of the structures for collective representation. In non- 


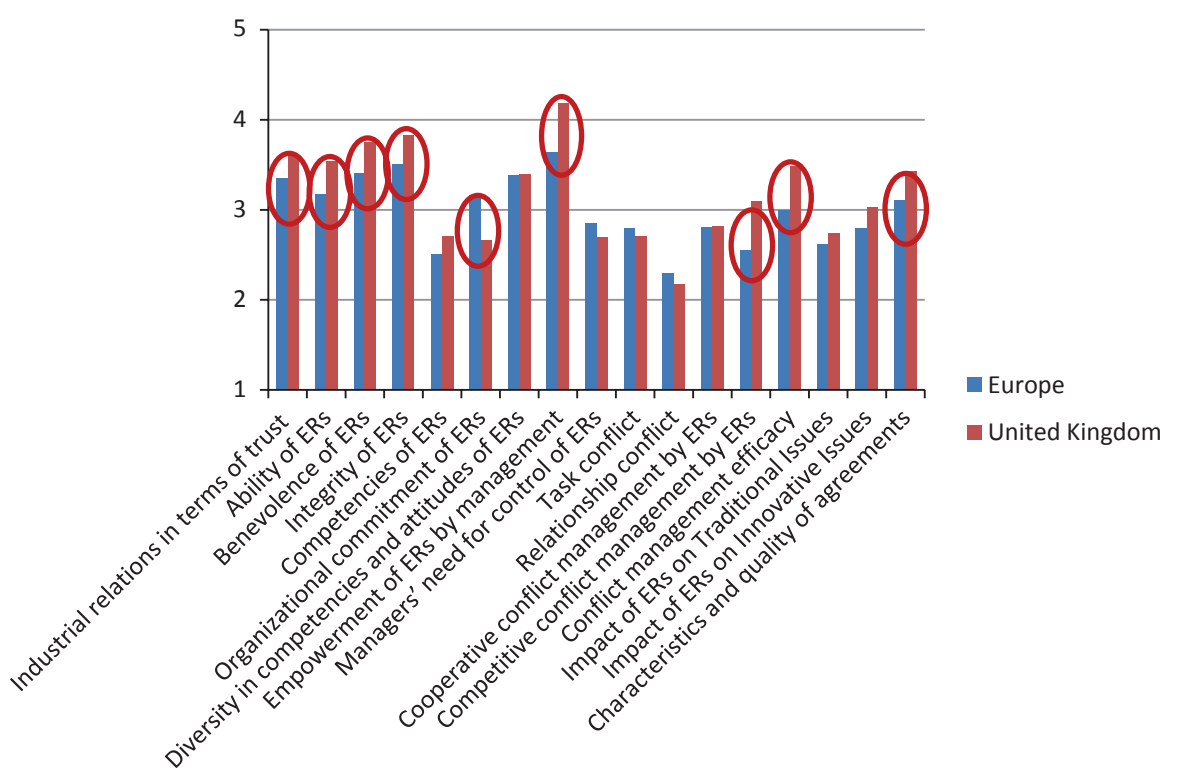

Fig. 12.1 Mean scores of main variables for UK and European HR managers

union organizations, it may simply refer to the 'absence' of conflictual industrial relations through collective bargaining or to the more limited remit of the forums and the greater tendency of UK workers to adopt (or be forced to adopt) a 'businessfriendly' perspective, as described by some interviewees. This may also be captured by the higher score on competitive conflict management $(\mathrm{M}=3.09 \mathrm{vs} . \mathrm{M}=2.59)$ and conflict management efficacy $(\mathrm{M}=3.48$ vs. $\mathrm{M}=2.98)$. The support for employee representatives by the responding managers (empowerment of employment representatives by management) is also substantially higher $(\mathrm{M}=4.18$ vs. $\mathrm{M}=3.61)$. Finally, the UK respondents were rather positive about the ability $(\mathrm{M}=3.54$ vs. $\mathrm{M}=3.14)$, benevolence $(\mathrm{M}=3.75$ vs. $\mathrm{M}=3.35)$ and integrity $(\mathrm{M}=3.83$ vs. $\mathrm{M}=3.47)$ of ERs. However, these positive impressions are somewhat countered by the low score on organizational commitment $(M=2.66$ vs. $M=3.16)$. As mentioned, we have to be careful when interpreting this data, also because of the low number of responses. Two factors may be of particular importance. First of all, these findings may be explained by the smaller remit of social dialogue in many UK organizations compared to those in continental Europe. This can imply less room for conflict, greater 'empowerment' by management, and lower requirements on the capabilities of the participants. Secondly, we have to remember that the findings may have been colored by the fact that many UK organizations have no recognized ERs and that the positive outcomes reflect the fact that respondents have compared the situation in their firms to this wider UK environment with limited representation. As such the findings are not necessarily representative but may need to be interpreted in com- 
parison to other UK rather than to other European firms. This suggests the need for further research and extreme care when interpreting the survey outcomes.

\subsection{HR Managers' Suggestions for Improving Social Dialogue}

There were various suggestions for improvements from the point of view of those managers driving or overseeing the systems of participation. While in the main they seemed to have positive experiences with the systems of participation, there were concerns with some aspects of their development. Particularly in the case of employee forums, these concerns tended to focus on the lack of formality in some of the structures and the problem of agenda setting, including the ability of members to represent the concerns of workers.

The costs of a more flexible approach to participation - especially in the private sector-were related to ongoing issues of sustainability. In the case of the housing trust the HR manager was concerned with the lack of formality and procedure. It was also common for interviewees to express concern about the lack of ability and capability of representatives, and the need for a more elaborate remit for the representative council. This was the case for the charity and the housing trust. The general concern was that there needed to be a more systematic set of structures and support. The authors see this as a reflection of the informal and flexible nature of such systems. There was a strong voluntary aspect which while having some virtues could not always guarantee a systematic and meaningful culture of participation in the longer term. In the case of the charity the need for role models was indicative of the fact that there seemed to be no clear benchmarks or reference points in terms of participation and participants. Participation was forged in relative isolation.

The need to develop less personal/individual agendas and a better way for representatives to feed back to the employees were also raised. This may be a reflection of the lack of history and clarity in the processes of those more 'flexible' forms of representation. That representatives should not speak to a personal agenda but represent the concerns of the wider workforce was a common concern. This issue of informality and the lack of 'seriousness' was reflected in various instances, in terms of time management problems and the absence of organizational support. The more voluntary and flexible approaches to participation did not work within clear and stable boundaries in terms of agenda setting, the development of representatives or general support for them. This is partly due to the absence of any legal or external guidelines and expectations of what support representatives should have. Hence the advantages of flexibility in representation as perceived by managers were countered by serious issues of capability in the representatives. The authors would argue that there may be a link between these two factors.

Even in larger private sector organizations there were concerns as to the quality or even absence of representatives further down operational structures. Incentives for engaging with participation and becoming a representative were not always ap- 
parent. There were references to the failure to explain the purpose of participation in cases where TUs were weaker or non-existent. The absence of a greater organizational effort in presenting the purpose and value of participation was lamented. In one high profile MNC the meetings of the forum would be held in different sites as a way of raising the profile of the forum within the firm, while also bonding the representatives together within the different activities and cultures of the firm. This was an unusual strategy for embedding the forum within the realities of the firm. In other cases there were attempts at creating informal relations and dialogues through 'away days' and joint training sessions as a way of promoting a more productive and trusting dialogue. In some cases, this was also a recognition of the need to extend the remit and purpose of participation.

Various interviewees in the public and private sector were concerned about the failure of middle and line management to engage with a participative approach. Some felt that more could be done to develop a greater management awareness of the work of the forums. While training was provided for representatives there was concern about the need for a greater investment in management and worker development in relation to the role and purpose of participation. The city council and one of the MNCs raised this as a major challenge. This could be one of the reasons why few workers came forward as representatives. The training discussed in the interviews was for members of the specific councils but there was a real challenge - or lack of interest - in raising awareness about the role of forums in some cases. Previous findings (Munduate et al. 2012) also highlighted that new worker representative roles were increasingly stressful due to competing demands in terms of communication, representation, changing workplace politics (e.g. equality), and the pressures of time at work. This confirms how investment in participation is a major issue.

\subsection{Discussion and Analysis}

The UK appears to exhibit different characteristics compared to Europe when we discuss questions of participation, with the more 'flexible' and company-led approaches very apparent. An interesting finding is that regardless of their variety such structures can on occasion shape decisions. All interviewees recognized such an influence. Yet at the same time, it is clear that the remit of the councils is often limited (which was particularly explicit in some of the MNCs) with many key issues not on the agenda (e.g. pay and bonuses). While it is clear that many forum or council structures perform reasonably well, management plays a major role in setting or shaping the agenda, and sometimes even the membership, especially with regards to the link with TUs and whether individuals can stand for election as trade unionists or as individuals.

The findings also show a clear and sharp divide between the traditionally unionized and public sector cases on the one hand, and the private sector cases on the other. In theory the depth, extent of dialogue and level of employee representative experience is much greater in the former. The nature of dialogue is broader even though 
the current political context is presenting a series of challenges. In the private sector, it appeared that the employee relations managers had a more steering and leading role. Even when the firms were unionized there appeared to be a clearer steering of the processes of dialogue and there were less risks taken by opening extensive strategic discussions with employee representatives. However, the commitment to collective representation in general appeared to be significant among HR managers. Many had wide experience of dealing with unions and representation. The attitudes were deemed to be positive, but we only have an HRM perspective so cannot verify this. However, the level of competence and understanding of the HR managers on such issues was notable.

The forums played many roles in terms of dealing with some key issues and in creating a climate or appearance of dialogue. They were important in legitimizing management decision making. To some extent this dominant position of management is countered by the need for the forums to appear to be successful. The 'better' organizations also stressed how the forums or councils were an essential instrument in improving communication and engagement. The forums were developed to enhance operational HRM activities through general discussion or through the promotion of sub-groups that dealt with problem-solving or developing specific features of HR practice such as discipline and grievance mechanisms. Some organizations (e.g. the housing trust) appeared highly sincere in their attempts to extend the remit of the forum to include more strategic issues. One of the Petrochemical MNCs also stressed how participation through the employee forum played an essential role in its overall HRM and contributed to a culture of employee engagement. However, these ambitions also confirm how the initiative, in defining the scope of participation, lies principally with management.

The main risks to the system rest in its fragmented nature. There is no clear pattern of representation as it varies by sector and organization, and even within them. In addition, the forums examined, while in the main established and functioning well, did not always have a clearly independent role in the private sector cases. There are also potential problems with the question of time. In the private sector the time available for such work was variable and not always adequate, while in the public sector time-off for industrial relations work is being questioned by the government and creating political unease. All these aspects illustrate how the virtues of 'flexible representation' are challenged by the difficulty of sustaining a coherent approach across time.

We must also keep in mind that these cases were open to interviews on what is normally a very sensitive topic in the UK and we are therefore unlikely to have captured many of the weaker cases and problems associated with a fragmented system of representation and participation. These organizations were open and willing to engage in a discussion with researchers and thus are likely to reflect the relatively more advanced side of participation. Many firms are not like this. The evidence on the whole is positive about the role of ERs but uncertain about the extent of the effectiveness of the UK's system of employee representation in non-union or non-collective systems. The ability of representatives from a non-trade union background to engage in a systematic and professional manner was a concern, and in those cases beyond the public sector it required extensive investment in training. 
What did strike us, regardless of the diversity and tensions in terms of participation, was that the managers in those cases where there were no unions or weaker unions, having engaged with the question of participation, still needed to ensure that the legitimacy of participation was developed. Even if agendas and individuals were not as independent as one would have liked, the presence of forums and representatives brought forward a need for pre-meetings, processes of feedback, elections to guarantee representativeness and continuity, clear agenda setting, the development of core individual representatives and regular and even innovative meetings. In effect, management had to be seen to enact such vignettes of participation and the perceived culture of it. If anything this approach has to be a specific focus of attention in those cases where organizations have decided not to develop or allow independent TU-based participation. In these cases they have to ensure that the memory or practice of collective mechanisms is recreated so as to justify the remit of the forums. This raises the question as to whether it would be easier to provide more space for independent representation and minimize the costs and bureaucratic controls within the management-led cases.

Open Access This chapter is distributed under the terms of the Creative Commons Attribution Noncommercial License, which permits any noncommercial use, distribution, and reproduction in any medium, provided the original author(s) and source are credited.

\section{References}

Alonso, L. E. (2001). New myths and old practices: postmodern management discourse and the decline of Fordist industrial relations. Transfer: European Review of Labour and Research, 7, 268-288.

Crouch, C. (1993). Industrial relations and European state traditions. Oxford: Oxford University Press.

European Commission (2009). Industrial relations in Europe 2008. Brussels: European Commission.

Gallie, D. (2007). Production regimes, employment regimes, and the quality of work. In D. Gallie (Ed.), Employment regimes and the quality of work. Oxford: Oxford University Press, pp. 1-34.

Hall, P. A., \& Soskice, D. W. (Eds.). (2001). Varieties of capitalism: The institutional foundations of comparative advantage. Oxford: Oxford University Press.

Hyman, R. (2001). Understanding European trade unionism: Between market, class and society. London: Sage.

Marchington, M., \& Wilkinson, A. (2005). Direct participation and involvement: Managing human resources: Personnel management in transition. In S. Bach (Ed.), Managing human resources (pp. 398-423). Oxford: Blackwell.

Martínez-Lucio, M., \& Stuart, M. (2005). Partnership 'and new industrial relations in a risk society an age of shotgun weddings and marriages of convenience? Work, Employment \& Society, 19(4), 797-817.

Martínez-Lucio, M., \& Stuart, M. (2007). Sustaining new industrial relations in the public sector: The politics of trust and co-operation in the context of organizational dementia and disarticulation. In P. Dibben, P. James, I. Roper \& G. Wood (Eds.). Modernising work in public services. Basingstoke: MacMillan Palgrave.

Meardi, G. (2004). Modelli o stili di sindacalismo in Europa? Stato e Mercato, 71, 207-235. 
Munduate, L., Euwema, M., \& Elgoibar, P. (2012). Ten steps for empowering employee representatives in the new European industrial relations. Madrid: McGraw Hill.

Oxenbridge, S., \& Brown, W. (2002). The two faces of partnership? An assessment of partnership and co-operative employer/trade union relationships. Employee Relations, 24(3), 262-276.

Perrett, R. (2007). Worker voice in the context of the re-regulation of employment: Employer tactics and statutory union recognition in the UK. Work, Employment \& Society, 21(4), 617-634. Sheldrake, J. (1988). The origins of public sector industrial relations. Aldershot: Avebury.

Visser, J. (1996). Traditions and transitions in industrial relations: a European view. In J. Van Ruysseveldt \& J. Visser (Eds.), Industrial relations in Europe: Traditions and transitions (pp. 1-41). London: Sage. 